\title{
Asherman's syndrome: current perspectives on diagnosis and management
}

This article was published in the following Dove Medical Press journal:

International Journal of Women's Health

\author{
Eva Dreisler \\ Jens Joergen Kjer \\ Department of Gynecology, \\ The Juliane Marie Centre, \\ Rigshospitalet, University of \\ Copenhagen, Copenhagen, Denmark
}

Correspondence: Jens Joergen Kjer Department of Gynecology, The Juliane Marie Centre, Rigshospitalet, University of Copenhagen, Dyssegaardsvej 76, DK-2870 Dyssegaard, Denmark

Tel +45202064I2

Fax +4535454005

Email jejk@mail.dk

\begin{abstract}
Intrauterine adhesions with symptoms like hypomenorrhea or infertility are known under the term Asherman's syndrome. Although the syndrome has been widely investigated, evidence of both prevention of the syndrome and the ideal treatment are missing. Understanding the pathogenesis of intrauterine adherences is necessary for the prevention of the formation of intrauterine scarring. Intrauterine adhesions can develop from lesion of the basal layer of the endometrium caused by curettage of the newly pregnant uterus. The syndrome may also occur after hysteroscopic surgery, uterine artery embolization or uterine tuberculosis. For initial diagnosis the less invasive contrast sonohysterography or hysterosalpingography is useful. The final diagnosis is based on hysteroscopy. Magnetic resonance imaging is required in cases with totally obliterated uterine cavity. Intrauterine adherences are classified in accordance with different classification systems based on the hysteroscopic diagnosis of severity and localization of adherences. Classification is necessary for the planning of surgery, information on prognosis and scientific purposes. Surgery is performed in symptomatic patients with either infertility or with painful periods. Intrauterine adherences are divided with a hysteroscope using scissors or a power instrument working from the central part of the uterus to the periphery. Peroperative ultrasonography is useful in an outpatient setting for the prevention of complications. Hysteroscopy with fluoroscopy is a solution in difficult cases. Use of intrauterine devices like balloon catheters or intrauterine contraceptive devices seems to be the preferred methods for the prevention of re-occurrence of adhesions after treatment. Both primary prevention after hysteroscopic surgery or curettage and secondary prevention of new adhesions after adhesiolysis have been investigated. The aim of this review was to summarize the literature on diagnosis, classification, treatment and prevention, based on a literature search with a wide range of search terms.
\end{abstract}

Keywords: Asherman's syndrome, genital adhesions, intrauterine synechia, gynatresia

\section{Introduction}

Intrauterine adhesions causing amenorrhea after curettage were first described by Fritsch in $1894 .{ }^{1}$ Later Asherman ${ }^{2}$ in 1950 described the history of 29 women with amenorrhea secondary to trauma of the uterine cavity, the Asherman's syndrome (AS). AS is defined by the presence of intrauterine adhesions or adhesions in the endocervix with consequent risk of hypomenorrhea/amenorrhea, reduced fertility, pregnancy loss and abnormal placentation.

The recently pregnant uterus seems susceptible to trauma of the basal layer of the endometrium, which can develop into intrauterine adhesions and may give future problems for the patient. It is estimated that more than $90 \%$ of cases with AS occur after pregnancy-related curettage. ${ }^{3}$

However, AS can develop without preceding pregnancy in cases with infection or surgery related to the uterus. 
Hanstede et $\mathrm{al}^{4}$ emphasizes that the presence of symptoms is essential for the term "Asherman's syndrome," as the increasing use of diagnostic hysteroscopy often will disclose clinically irrelevant adhesions.

In cases where intrauterine adhesions (IUA) are found accidentally without any symptoms one should avoid the term AS and instead apply the term "asymptomatic intrauterine adhesions."

Intrauterine adhesions can be either primary after pregnancy-related curettage, alternatively after hysteroscopic surgery, or secondary when re-occurring after adhesiolysis has been performed. ${ }^{6,7}$

Although AS has been known for many years we still lack reliable non-invasive diagnostic methods, agreement about one classification only and sufficient methods to avoid re-occurrence of adhesions after surgical treatment of AS.

All eligible literature until September 2018 was identified using the keywords "Asherman's syndrome," "genital adhesions," "intrauterine synechiae," and "gynatraesia" and reviewed by electronic databases including PubMed, Web of Science and Scopus. Other relevant articles were found from citations in these publications. The selection of relevant papers based on the literature search is illustrated in the flowchart (Figure 1). Excluded were non-English papers, studies of vagina, experimental and animal studies, most case-stories, minor case-series and reviews, except meta-analyses. Animal studies and experimental studies are included in the paragraph about stem cell treatment.

\section{Occurrence}

It is impossible to detect or estimate the true prevalence of all IUA, as probably most cases are without symptoms. However, the total number is irrelevant from a practical point of view. Only cases with AS, which imply pain, bleeding disorders or impaired fertility needs treatment.

Prevalence is dependent on the population studied as well as the diagnostic method and classification systems used. Thus, the prevalence is difficult to define as the diagnostic methods have changed over time and different classifications are used. If we wish to determine whether the prevalence is changing, we should at least agree about definition and classification.

Among an infertile population Baradwan et $\mathrm{al}^{8}$ found the prevalence of AS to be $4.6 \%$. After secondary removal of placental remnants or repeat curettage after incomplete abortion a prevalence of IUA was found in 40\%. ${ }^{9}$ Salzani et $\mathrm{al}^{10}$ found IUA in $37.6 \%$ after curettage following abortion. The incidence of IUA varies between 15 and $40 \%$

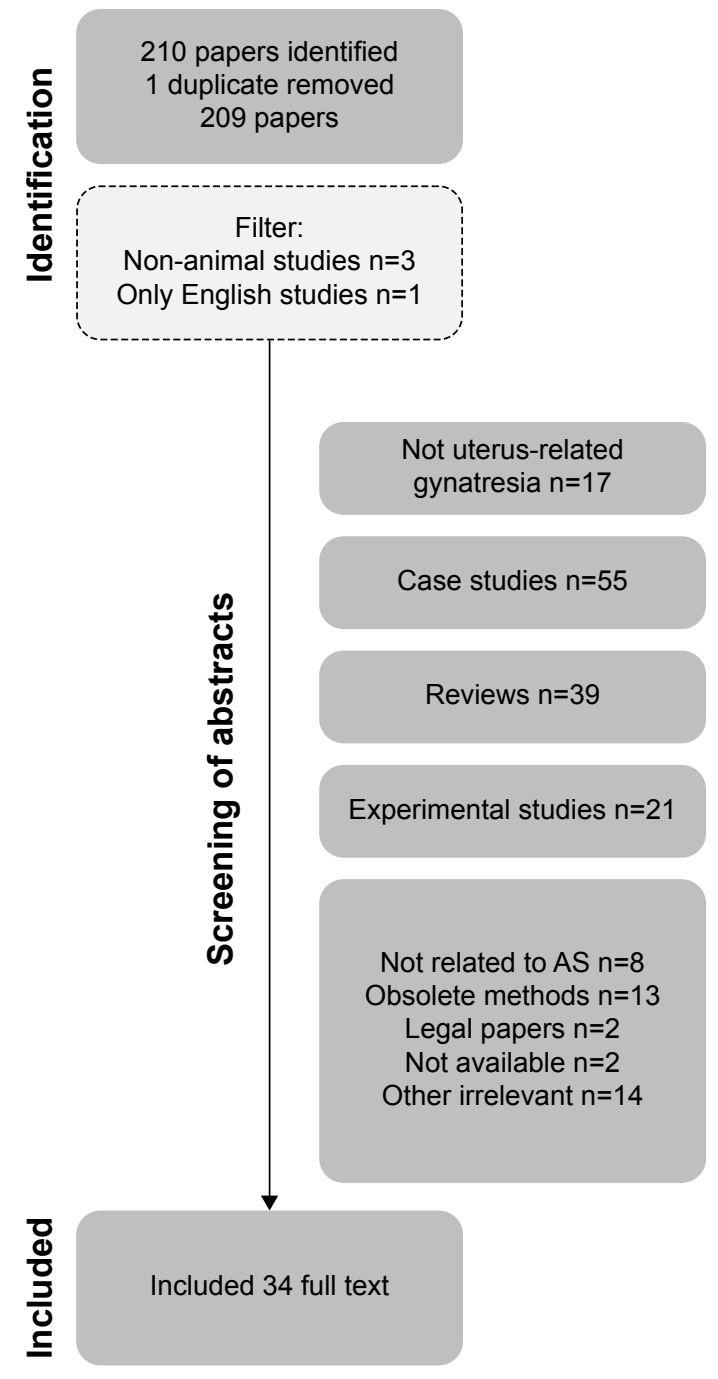

Figure I Selection of relevant papers for the study. Abbreviation: AS, Asherman's syndrome.

after curettage. ${ }^{10}$ The prevalence of AS in women with impaired fertility ranges from $2.8 \%$ to $45.5 \%$ depending on the subpopulation. ${ }^{11}$ In a meta-analysis by Hooker et al ${ }^{12}$ a prevalence of IUA of $19.1 \%$ was found by hysteroscopy within 1 year in women diagnosed with miscarriage treated expectantly, medically or surgically. The majority were mild to moderate adhesions. The incidence of AS has been investigated in different populations. Applying a strict definition, the incidence should only imply new cases in a given period. However, very often the cases described concern treatment of reoccurrences, often multiple treatments. In Denmark a total of 61 unique cases of AS was found during a 10-year period, ${ }^{13}$ in Holland 638 women with AS were referred to a specialist center during a 10-year period ${ }^{4}$ and in Saudi Arabia, 41 women were referred with AS to a specialist center during an 8 -year period. ${ }^{8}$ Chen et al ${ }^{14}$ found 357 cases of AS in a 4-year period in a large Women's Hospital in China. 


\section{Risk factors}

Trauma caused by surgical interventions, primarily curettage of the basal layer of the endometrium shortly after a pregnancy is the main reason for development of symptomatic IUA. These adhesions can result in partial or complete obstruction of the uterine cavity or the cervical canal. An incidence of $10 \%$ IUA after one curettage evaluated by HSG was seen in one randomized controlled trial. ${ }^{15}$ However, in women with at least two curettages $30.6 \%(22 / 72)$ had IUA when evaluated by hysteroscopy 10 weeks after the curettages. ${ }^{16}$

Two cohort studies including women with retained products of conception (RPOC) after delivery or miscarriage demonstrated significantly more IUAs after curettage compared to hysteroscopic removal (35.9\% vs $4.2 \%) .{ }^{9,17}$

Usually the trauma is caused by curettage intending to remove placental remnants after a recent pregnancy. Even ultrasound-guided curettage is more traumatic than hysteroscopy when emptying the uterine cavity. ${ }^{17}$ First trimester procedures appear to cause less severe adhesions, the majority grade 1-2 (ESGE classification) compared to postpartum procedures, where the majority had grade $3-5$ in one study.

The incidence of curettage-related IUA in women seeking termination of pregnancy may be declining. The national rate of surgical termination in Denmark has declined from $87 \%$ to $36 \%$ from 2001 to 2017 , as the rate of the more gently medical termination of a pregnancy has increased. Medical termination is insufficient in $4 \%$ of procedures leading to curettage. Surgical termination is insufficient in $2.7 \%$ leading to re-evacuation according to the National Danish Patient register, which covers all citizens and surgical procedures in Denmark. With these figures in mind the number of re-evacuations after legal abortion is more than halved (352 in 2001 and 145 in 2017) in Denmark from 2001 to 2017, as a consequence of increased use of medical abortions. Hopefully this reduced frequency of intrauterine trauma will result in fewer cases with AS in the future. ${ }^{18}$

Other procedures or circumstances may create intrauterine adhesions. Thus, case stories mention embolization of the uterus, B-Lynch sutures, abdominal myomectomy, hysteroscopic myomectomy, genital tuberculosis and surgical treatment of Mullerian anomalies. ${ }^{19-24}$

Furthermore, a predisposition to intrauterine adhesions could be linked to unspecific factors like age, race, nutritional status and infectious processes. ${ }^{25}$ However, such factors are not supported in the literature, where the dominant factor seems to be surgical trauma (frequent hysteroscopic surgery, repeat curettages and infection). ${ }^{9,25}$

\section{Diagnosis of intrauterine adherences}

Several diagnostic modalities have been evaluated for the diagnosis of intrauterine adhesions (IUA). IUA can be visualized by hysterosalpingography (HSG), ultrasonography including contrast sonohysterography (SHG), 3D ultrasonography, hysteroscopy and magnetic resonance imaging (MRI). Hysteroscopy is the gold standard in studies comparing different diagnostic modalities, and several classification systems are based on hysteroscopic findings. HSG gives the opportunity to simultaneously evaluate tubal patency, but details of filling defects are not visualized, and a high false-positive rate is documented. ${ }^{26,27}$ Transvaginal ultrasonography with evaluation of the endometrial thickness in women with AS showed substantially thinner endometrium compared to normal menstruating women, in a study of 16 women with AS and 50 controls. ${ }^{28}$ Unenhanced transvaginal ultrasonography alone has very limited diagnostic capacity, ${ }^{29}$ with both sensitivity and positive predictive value as low as $0 \% .{ }^{27}$ Contrast sonohysterography with infusion of sterile saline or gel in the uterine cavity and dynamic ultrasonography enables visualization of the uterine cavity. ${ }^{30}$ Contrast sonohysterography has a high negative predictive value (98\%), but a moderate positive predictive value (43\%) when compared with hysteroscopy. ${ }^{27,29}$ In a Taiwanese study of 110 women, 3D sonography was compared with hysteroscopy, finding a confirmation range of $16 \%-100 \%$ in accordance to the number of morphological abnormalities, including marginal irregularity, thinning defects, obliteration, fibrosis and calcification..$^{31}$ Virtual hysteroscopy, a 4D virtual reconstruction of the uterine cavity may play a future role in the diagnosis of IUA. ${ }^{32} \mathrm{HSG}, \mathrm{SHG}$ and hysteroscopy are all of limited diagnostic value when the cavity is totally obstructed. In these rare cases MRI can be valuable, although too expensive as a routine diagnostic tool. ${ }^{33,34}$ The application of ultrasound contrast for three-dimensional color power angiography has been evaluated in one study only. ${ }^{35}$ When compared with hysteroscopy a positive likelihood ratio of 2.9 for detection of IUA was found, meaning moderate diagnostic ability. These findings have not been confirmed by others. Intraoperative fluoroscopy improves the imaging during surgery and is now preferred instead of simultaneous laparoscopy. ${ }^{4}$

\section{Classification of IUA and AS}

Several classification systems have been proposed for the description of the severity of IUA and AS. ${ }^{36-42}$ They are all descriptive in different ways and are therefore non-comparable. Only two classification systems include 
symptoms regarding AS (obstetric or menstrual history). Three of the classifications are descriptive with three stages: minimal/mild, moderate, and severe based on the hysteroscopic assessment of the extent and type of adhesions (filmy, firm/dense). ${ }^{36,38,39}$ Hamou et $\mathrm{al}^{37}$ describe the adhesions as isthmic, marginal, central, and severe. The former European Society for Hysteroscopy ${ }^{41}$ operated with four grades with subtypes (seven stages in all), while Donnez ${ }^{40}$ uses six grades based on hysteroscopy and HSG with postoperative pregnancy rate as primary driver. Finally, Nasr et $\mathrm{al}^{42}$ have developed a complex system with hysteroscopic assessment combined with menstrual and obstetric history. None of the used classification systems have been validated or examined in relation to reproductive performance.

Intending to produce valid data for evaluation of treatment and prophylaxis, it is mandatory to agree about one of the systems. The ideal system should include extent and type of adhesions as well as fertility history, menstrual history is in our opinion less important.

\section{Management of AS Prevention of IUA after curettage}

In an industry-sponsored randomized controlled trial there was significantly less IUA in women undergoing curettage with at least one previous curettage when hyaluronic acid gel was applied. However, selection bias may be present in the study of 149 women collected from eight different centers in a 3-year period, ie, six patients per center per year. ${ }^{16}$ In a recent study of suction curettage in delayed miscarriage a significant reduction of moderate to severe IUA was seen in women treated with a new crosslinked hyaluronan gel finding $0.7 \%$ (1/137) vs $24 \%$ (33/137) respectively. ${ }^{43}$ However these findings should be confirmed by future studies.

\section{Prevention of IUA after hysteroscopic procedures}

Taskin et $\mathrm{al}^{44}$ found a high frequency of IUA after resection of solitary and multiple fibroids (31.3\% respectively 45.5\%). In another study, Mazzon et $\mathrm{al}^{45}$ found a very low frequency of IUA after myomectomy with a combination of monopolar current and cold knife resection. The incidence of formation of IUA after resection of uterine septum is estimated to be up to $12 \%$ in untreated women. ${ }^{21}$ In three prospective randomized studies, the administration of oral estrogen did not reduce the risk of IUA. ${ }^{21,46,47}$ Hyaluronic acid gel or polyethylene oxide-sodium carboxymethylcellulose gel for the prevention of intrauterine adherences have been investigated demonstrating conflicting results. In a meta-analysis it is concluded that there is lack of reproducible evidence to prove that gel may decrease IUA after hysteroscopy. ${ }^{48}$

\section{Treatment of AS}

In women with infertility and those with painful hypo-/ amenorrhea, treatment of AS is indicated. For fertility, the initial goal of treatment is restoration of a normal calibrated uterine cavity covered with endometrial lining and free tubal ostia. However, further fertility treatment may be necessary, especially in cases where the tubes are blocked. In cases without infertility, where retained blood leads to cyclic pain, sufficient drainage is mandatory. As hysteroscopic equipment has improved over the years, hysteroscopic treatment has become the method of choice. ${ }^{38,49}$ Filmy adhesion alone can be divided by using the tip of the hysteroscope without any energy source or scissors. ${ }^{49}$ The division of adhesions begins in the central and safe part of the uterus and moves laterally and toward the fundus.

Different hysteroscopic instruments are useful in the treatment of AS, biopsy forceps, sharp or blunt scissors ${ }^{4,11,38}$ and division of strings with energy like monopolar diathermia, ${ }^{50}$ bipolar diathermia ${ }^{51}$ or laser. ${ }^{52,53}$ Careful dissection with energy instruments is mandatory, as the energy may destroy otherwise healthy endometrium. Monopolar diathermia with special fluids is associated with a larger risk of fluid overload complications compared to bipolar diathermia with saline and therefore not recommended as first choice treatment. ${ }^{54}$

Few studies have evaluated the outcome after hysteroscopic adhesiolysis. Overall restoration of normal menstruation is observed in $75 \%-100 \%{ }^{4,38,50,55,56}$ The effect on fertility is influenced by several other factors, eg, the age of the patient, and whether infertility is primary or secondary. The pregnancy rate ranges between 25 and $76 \% \%^{38,56}$ and the term delivery rate, in women who achieved pregnancy, between 25 and $79.7 \%$. $^{38,56,57}$

The success rate is dependable on the severity of adhesions. ${ }^{38,50}$ The hysteroscopic procedure is feasible and can be performed in an outpatient setting. ${ }^{57}$ Intraoperative transabdominal ultrasonography, as an alternative to laparoscopy, can decrease complications in terms of perforation and false passageways. For severe cases intraoperative fluoroscopy with simultaneous X-ray is a possibility. Intracavitary distribution of contrast media facilitates visualization of hidden areas of endometrium and tubal patency can be evaluated during the procedure. The intraoperative fluoroscopy is an effective method to avoid uterine perforation, with better results than intraoperative ultrasonography., ${ }^{4,58}$ 
After primary hysteroscopic adhesiolysis, the formation of new adhesions is very frequent, and several modalities have been studied and suggested for the prevention of new adhesions. The recurrence rate is associated with the grade of adherences. Hanstede et al ${ }^{4}$ found $21 \%-25 \%$ recurrence with grade $1-2 \mathrm{a}$ adherences, $29.1 \%$ with grade 3 , $38.5 \%$ with grade 4 , and $41.9 \%$ with grade five using the classification system of the former European Society of Hysteroscopy.

Second-look hysteroscopy with division of newly formed adherences has been studied in a retrospective setting of 151 patients, cumulative pregnancy rate ( $77 \%$ vs $56 \%)$ and live birth rate ( $77 \%$ vs $63 \%$ ) seems to improve when early second-look is performed within 2 weeks to 2 months after primary adhesiolysis. ${ }^{59} \mathrm{~A}$ small observational study recommended second-look hysteroscopy after 2 weeks, and up to four hysteroscopies after primary surgery. In this report $46 \%(7 / 15)$ were either pregnant or had delivered an infant at the end of the study. ${ }^{60}$

There are several methods for secondary prevention. The use of estrogen has been studied in several set-ups, either as estrogen only ${ }^{55,61}$ or as ancillary treatment either with intrauterine device ${ }^{11,14,24,47,62-65}$ or Foley catheter. . $^{11,61,65}$

Increased menstrual flow was seen when estrogen was used as ancillary treatment, except in one study including genital tuberculosis ${ }^{66}{ }^{6}$ The effect on fertility depended upon the severity of AS and needs further investigation. ${ }^{67} \mathrm{In}$ studies where estrogen was used alone, pregnancy rates were generally lower $(42 \%-53 \%)^{51,61,68}$ compared to the ancillary use of estrogen with intrauterine contraceptive device (IUCD), Foley catheter or other device, where pregnancy rates were $51 \%-100 \% .^{14,61,62,65}$ Varying regimes of estrogen were used in the studies, leaving no conclusion on ideal dosage, timing of progesterone or route of administration (vaginal or oral). In a recent randomized study, $4 \mathrm{mg}$ and $10 \mathrm{mg}$ estradiol orally was compared. No superior effect of the high dosage was demonstrated. ${ }^{69}$ When comparing $2 \mathrm{mg}$ and $6 \mathrm{mg}$ in a prospective, randomized trial, no benefit was demonstrated in the $6 \mathrm{mg}$ arm. ${ }^{70}$

Intrauterine application of gel for secondary prevention of adhesions has been investigated. Acunzo et al found a significant effect of hyaluronic acid compared to no treatment (14\% in the hyaluroic acid arm, 32\% in the no treatment arm $P<0.05)$ in the only randomized controlled trial of gel barrier for prevention of new IUA after hysteroscopic adhesiolysis. ${ }^{71}$ A study comparing intrauterine balloon, IUCD and hyaluronic acid gel demonstrated that the balloon and IUCD were more effective than hyaluronic acid when evaluated with AFS score. No data on menstrual flow or fertility were presented. ${ }^{72}$

The use of other mechanical barriers is also suggested for the prevention of secondary adhesions. Orhue et al ${ }^{62}$ compared an IUCD with a pediatric Foley catheter and found that the catheter was significantly more effective in terms of restoring normal menstruation and conception. The shortterm use of the two devices was analyzed in two periods, each lasting 4 years. Cook Medical (Indianapolis, IN, USA) has designed a heart-shaped intrauterine balloon for prevention of secondary intrauterine adhesions. March ${ }^{73}$ argues that this balloon is more effective in the prevention of marginal intrauterine adhesions than the Foley catheter. Lin et $\mathrm{al}^{72}$ found in a blinded RCT study that balloon and IUCD were equally effective in the prevention of secondary adhesions.

The same group performed a retrospective cohort study comparing balloon, IUCD, hyaluronic acid and controls. In this study they were not able to detect a difference between balloon and IUCD. However, these two modalities were significantly more effective than hyaluronic acid. Hyaluronic acid was no better than no prophylaxis in the controls. ${ }^{72}$

\section{Infection and antibiotics}

According to the literature the only specific infection that causes AS is genital tuberculosis. ${ }^{19}$ There is no evidence in the literature that prophylactic antibiotics can prevent secondary intrauterine infectious complications ${ }^{87}$ However, when obvious infection is seen, antibiotics are mandatory.

\section{Stem cell treatment in AS}

Regeneration of endometrium through stem cell treatment has been evaluated both in animal models ${ }^{74-78}$ and in small experimental human studies. ${ }^{79-82}$ Bone-marrow derived stem cells, mesenchymal stem cells and autologous menstrual blood derived stromal cells have been investigated. Different application methods have been used, eg infusion in spiral arterioles through catheters,${ }^{81}$ transmyometrial administration to the subendometrial area ${ }^{80}$ and direct installation of stromal cells in uterine cavity after endometrial scratching. ${ }^{82}$ Stem cells arranged in spheroids were successful in a rat model of damaged endometrium. ${ }^{78}$ In a study by Singh et a ${ }^{80}$ five out of six women started menstruation again. Santa Maria et a ${ }^{81}$ included 15 women with AS, who attained increased endometrial thickness and regular menses with hormonal replacement therapy. Four women conceived, one with a live birth. In the study of Tan et a ${ }^{82}$ seven women with refractory AS who were treated with autologous menstrual bloodderived stromal cells, had increased endometrial thickness. 
Three patients conceived, with one on-going pregnancy. Future randomized trials are needed to prove if stem cell treatment will have a clinical role in AS.

\section{Complications of AS}

When fertility is restored after treatment of AS, even obstetric complications may occur, eg reduced fetal weight and placenta-related complications. Only one case-control study describes the potential hazards for the foetus when the mother had IUA. ${ }^{83}$ This study found a significantly lower birthweight in cases with IUA, increased incidence of preterm delivery and retained placenta in $10.7 \%$ of the patients. However, the material only comprises 14 cases and 42 controls. Preterm delivery was also described by Roy et $\mathrm{al}^{47}$ and Zikopoulos et $\mathrm{al}^{63}$ after surgical treatment of AS.

Friedman et $\mathrm{al}^{84}$ described three patients with placenta accreta, uterine sacculation and paper-thin uterine fundus in pregnancies after surgical treatment of intrauterine adhesions. Siegler and Valle ${ }^{85}$ found placenta accreta in $8 \%$ of pregnant women after treatment for AS. The occurrence of placenta accreta has only been described in the recent literature in case stories. ${ }^{86}$

\section{Conclusion}

The prevention and treatment of AS are still a challenge, as the syndrome appears only occasionally after termination of pregnancy and after emptying of the recently pregnant uterus.

Focus on the information about effective contraception is necessary to minimize the number of legal abortions. If legal abortion is indicated, the medical termination of pregnancy seems to reduce the frequency of surgical evacuation and re-evacuation and consequently might be less prone to induce intrauterine adhesions. If evacuation of retained products of conception is needed, it is important to be as gentle as possible without increasing the risk for re-evacuation and consequently increasing the risk of AS. In cases with RPOC, hysteroscopy is preferred due to the significantly reduced risk of IUA compared to curettage. Hysteroscopy is more effective in avoiding incomplete removal of RPOC.

AS should be suspected if the patient complains about change in menstrual pattern, menstrual pain or infertility after intrauterine instrumentation. Ultrasonography with saline infusion can in some cases show filling defects of the uterine cavity.

If AS is suspected, a hysteroscopy should be performed, and adhesions should be separated without use of electric current or with bipolar current to prevent complications.

To avoid re-occurrence of adhesions the use of balloon catheters or IUCD (without progesterone) seems advisable.
Complementary treatment with low-dose estrogen might be helpful.

AS is rather infrequent, and the surgery is difficult. Therefore, it is important to refer severe cases to specialized centers with surgeons skilled in advanced intrauterine surgery.

\section{Disclosure}

The authors report no conflicts of interest in this work.

\section{References}

1. Fritsch H. Ein fall von volligen Schwund Der Gebärmutterhohle nACh Auskratzung. Zentralbl Gynaekol. 1894;18:1337-1342.

2. Asherman JG. Traumatic intra-uterine adhesions. J Obstet Gynaecol Br Emp. 1950;57(6):892-896.

3. Schenker JG, Margalioth EJ. Intrauterine adhesions: an updated appraisal. Fertil Steril. 1982;37(5):595-610.

4. Hanstede MMF, van der Meij E, Goedemans L, Emanuel MH. Results of centralized Asherman surgery, 2003-2013. Fertil Steril. 2015; 104(6):1561-1568.

5. Yu D, Wong YM, Cheong Y, Xia E, Li TC. Asherman syndrome-one century later. Fertil Steril. 2008;89(4):759-779.

6. Diamond MP, Freeman ML. Clinical implications of postsurgical adhesions. Hum Reprod Update. 2001;7(6):567-576.

7. Hellebrekers BW, Trimbos-Kemper TC, Trimbos JB, Emeis JJ, Kooistra T. Use of fibrinolytic agents in the prevention of postoperative adhesion formation. Fertil Steril. 2000;74(2):203-212.

8. Baradwan S, Baradwan A, Al-Jaroudi D. The association between menstrual cycle pattern and hysteroscopic March classification with endometrial thickness among infertile women with Asherman syndrome. Medicine. 2018;97(27):e11314.

9. Westendorp IC, Ankum WM, Mol BW, Vonk J. Prevalence of Asherman's syndrome after secondary removal of placental remnants or a repeat curettage for incomplete abortion. Hum Reprod. 1998;13(12):3347-3350.

10. Salzani A, Yela DA, Gabiatti JRE, Bedone AJ, Monteiro IMU. Prevalence of uterine synechia after abortion evacuation curettage. Sao Paulo Med J. 2007;125(5):261-264.

11. March CM, Israel R, March AD. Hysteroscopic management of intrauterine adhesions. Am J Obstet Gynecol. 1978;130(6):653-657.

12. Hooker AB, Lemmers M, Thurkow AL, et al. Systematic review and meta-analysis of intrauterine adhesions after miscarriage: prevalence, risk factors and long-term reproductive outcome. Hum Reprod Update. 2014;20(2):262-278.

13. Kjer JJ. Asherman syndrome in a Danish population. Acta Obstet Gynecol Scand. 2014;93(4):425-427.

14. Chen L, Zhang H, Wang Q, et al. Reproductive outcomes in patients with intrauterine adhesions following hysteroscopic adhesiolysis: experience from the largest women's hospital in China. J Minim Invasive Gynecol. 2017;24(2):299-304.

15. Tsapanos VS, Stathopoulou LP, Papathanassopoulou VS, Tzingounis VA. The role of Seprafilm bioresorbable membrane in the prevention and therapy of endometrial synechiae. J Biomed Mater Res. 2002;63(1): $10-14$.

16. Hooker AB, de Leeuw R, van de Ven PM, et al. Prevalence of intrauterine adhesions after the application of hyaluronic acid gel after dilatation and curettage in women with at least one previous curettage: short-term outcomes of a multicenter, prospective randomized controlled trial. Fertil Steril. 2017;107(5):1223-1231.

17. Rein DT, Schmidt T, Hess AP, Volkmer A, Schöndorf T, Breidenbach M. Hysteroscopic management of residual trophoblastic tissue is superior to ultrasound-guided curettage. J Minim Invasive Gynecol. 2011;18(6): 774-778.

18. Early pregnancy complication and abortion database [Danish]. Available from: https://www.sundhed.dk/content/cms/67/4667_tigrab_ aarsrapport_2017_offentlig.pdf. Accessed March 13, 2019. 
19. Sharma JB, Roy KK, Pushparaj M, et al. Genital tuberculosis: an important cause of Asherman's syndrome in India. Arch Gynecol Obstet. 2008;277(1):37-41.

20. Goojha CA, Case A, Pierson R. Development of Asherman syndrome after conservative surgical management of intractable postpartum hemorrhage. Fertil Steril. 2010;94(3):1098.e1-1098.e5.

21. Tonguc EA, Var T, Yilmaz N, Batioglu S. Intrauterine device or estrogen treatment after hysteroscopic uterine septum resection. Int J Gynaecol Obstet. 2010;109(3):226-229.

22. Papoutsis D, Georgantzis D, Daccò MD, et al. A rare case of Asherman's syndrome after open myomectomy: sonographic investigations and possible underlying mechanisms. Gynecol Obstet Invest. 2014;77(3): 194-200.

23. Song D, Liu Y, Xiao Y, Li T-C, Zhou F, Xia E. A matched cohort study comparing the outcome of intrauterine adhesiolysis for Asherman's syndrome after uterine artery embolization or surgical trauma. J Minim Invasive Gynecol. 2014;21(6):1022-1028.

24. Yu X, Yuhan L, Dongmei S, Enlan X, Tinchiu L. The incidence of postoperative adhesion following transection of uterine septum: a cohort study comparing three different adjuvant therapies. Eur J Obstet Gynecol Reprod Biol. 2016;201:61-64.

25. di Spiezio Sardo A, Calagna G, Scognamiglio M, O’Donovan P, Campo R, de Wilde RL. Prevention of intrauterine post-surgical adhesions in hysteroscopy. A systematic review. Eur J Obstet Gynecol Reprod Biol. 2016;203:182-192.

26. Roma Dalfó A, Úbeda B, Úbeda A, et al. Diagnostic value of hysterosalpingography in the detection of intrauterine abnormalities: a comparison with hysteroscopy. AJR Am J Roentgenol. 2004;183(5):1405-1409.

27. Soares SR, Barbosa dos Reis MM, Camargos AF. Diagnostic accuracy of sonohysterography, transvaginal sonography, and hysterosalpingography in patients with uterine cavity diseases. Fertil Steril. 2000; 73(2):406-411.

28. St L, Ramsay P, Pierson R, et al. Endometrial thickness measured by ultrasound in women with uterine outlet obstruction due to intrauterine or upper cervical adhesions. Human Reprod. 2008;23(2):306-309.

29. Salle B, Gaucherand P, de Saint Hilaire P, Rudigoz RC. Transvaginal sonohysterographic evaluation of intrauterine adhesions. J Clin Ultrasound. 1999;27(3):131-134.

30. Berridge DL, Winter TC. Saline infusion sonohysterography: technique, indications, and imaging findings. J Ultrasound Med. 2004; 23(1):97-112.

31. Kim MJ, Lee Y, Lee C, et al. Accuracy of three dimensional ultrasound and treatment outcomes of intrauterine adhesion in infertile women. Taiwan J Obstet Gynecol. 2015;54(6):737-741.

32. Tesarik J, Mendoza-Tesarik R, Mendoza N. Virtual ultrasonographic hysteroscopy followed by conventional operative hysteroscopy, enabling pregnancy. Am J Obstet Gynecol. 2017;216(2):188.e1.

33. Letterie GS, Haggerty MF. Magnetic resonance imaging of intrauterine synechiae. Gynecol Obstet Invest. 1994;37(1):66-68.

34. Bacelar AC, Wilcock D, Powell M, Worthington BS. The value of MRI in the assessment of traumatic intra-uterine adhesions (Asherman's syndrome). Clin Radiol. 1995;50(2):80-83.

35. Yan L, Wang A, Bai R, et al. Application of SonoVue combined with three-dimensional color power angiography in the diagnosis and prognosis evaluation of intrauterine adhesion. Eur J Obstet Gynecol Reprod Biol. 2016;198:68-72.

36. March CM, Israel R, March AD. Hysteroscopic management of intrauterine adhesions. Am J Obstet Gynecol. 1978;130(6):653-657.

37. Hamou J, Salat-Baroux J, Siegler AM. Diagnosis and treatment of intrauterine adhesions by microhysteroscopy. Fertil Steril. 1983;39(3): 321-326.

38. Valle RF, Sciarra JJ. Intrauterine adhesions: hysteroscopic diagnosis, classification, treatment, and reproductive outcome. Am JObstet Gynecol. 1988;158(6 Pt 1):1459-1470.

39. The American Fertility Society classifications of adnexal adhesions, distal tubal occlusion, tubal occlusion secondary to tubal ligation, tubal pregnancies, Müllerian anomalies and intrauterine adhesions. Fertil Steril. 1988;49(6):944-955.
40. Donnez J, Nisolle M. Hysteroscopic adhesiolysis of intrauterine adhesions (Asherman syndrome). In: Donnez J, editor. Atlas of Laser Operative Laparoscopy and Hysteroscopy. London, UK: Parthenon Publishing Group; 1994:305-322.

41. Wamsteker K. Diagnostic hysteroscopy: technique and documentation. In: Sutton CD, Diamond M, editors. Endoscopic Surgery for Gynecologists. London, UK: WB Saunders; 1998:511-524.

42. Nasr AL, Al-Inany HG, Thabet SM, Aboulghar M. A clinicohysteroscopic scoring system of intrauterine adhesions. Gynecol Obstet Invest. 2000;50(3):178-181.

43. Li X, Wu L, Zhou Y, et al. New crosslinked hyaluronan gel for the prevention of intrauterine adhesions after dilation and curettage in patients with delayed miscarriage: a prospective, multicenter, randomized, controlled trial. J Minim Invasive Gynecol. 2019;26(1):94-99.

44. Taskin O, Sadik S, Onoglu A, et al. Role of endometrial suppression on the frequency of intrauterine adhesions after resectoscopic surgery. J Am Assoc Gynecol Laparosc. 2000;7(3):351-354.

45. Mazzon I, Favilli A, Cocco P, et al. Does cold loop hysteroscopic myomectomy reduce intrauterine adhesions? A retrospective study. Fertil Steril. 2014;101(1):294-298.

46. Dabirashrafi H, Mohammad K, Moghadami-Tabrizi N, Zandinejad K, Moghadami-Tabrizi M. Is estrogen necessary after hysteroscopic incision of the uterine septum? J Am Assoc Gynecol Laparosc. 1996;3(4): 623-625.

47. Roy KK, Negi N, Subbaiah M, Kumar S, Sharma JB, Singh N. Effectiveness of estrogen in the prevention of intrauterine adhesions after hysteroscopic septal resection: a prospective, randomized study. J Obstet Gynaecol Res. 2014;40(4):1085-1088.

48. Healy MW, Schexnayder B, Connell MT, et al. Intrauterine adhesion prevention after hysteroscopy: a systematic review and meta-analysis. Am J Obstet Gynecol. 2016;215(3):267-275.

49. Sugimoto O. Diagnostic and therapeutic hysteroscopy for traumatic intrauterine adhesions. Am J Obstet Gynecol. 1978;131(5):539-547.

50. Pabuçcu R, Atay V, Orhon E, Urman B, Ergün A. Hysteroscopic treatment of intrauterine adhesions is safe and effective in the restoration of normal menstruation and fertility. Fertil Steril. 1997;68(6): 1141-1143.

51. Fernandez H, Gervaise A, de Tayrac R. Operative hysteroscopy for infertility using normal Saline solution and a coaxial bipolar electrode: a pilot study. Hum Reprod. 2000;15(8):1773-1775.

52. Newton JR, Mackenzie WE, Emens MJ, Jordan JA. Division of uterine adhesions (Asherman's syndrome) with the Nd-YAG laser. $\mathrm{Br} J \mathrm{Obs}$ Gyn. 1989;96(1):102-104.

53. Chapman R, Chapman K. The value of two stage laser treatment for severe Asherman's syndrome. Br J Obstet Gynaecol. 1996;103(12): 1256-1258.

54. Istre O, Bjoennes J, Naess R, Hornbaek K, Forman A. Postoperative cerebral oedema after transcervical endometrial resection and uterine irrigation with 1.5\% glycine. Lancet. 1994;344(8931):1187-1189.

55. Capella-Allouc S, Morsad F, Rongières-Bertrand C, Taylor S, Fernandez H. Hysteroscopic treatment of severe Asherman's syndrome and subsequent fertility. Hum Reprod. 1999;14(5):1230-1233.

56. Yamamoto N, Takeuchi R, Izuchi D, et al. Hysteroscopic adhesiolysis for patients with Asherman's syndrome: menstrual and fertility outcomes. Reprod Med Biol. 2013;12(4):159-166.

57. Bougie O, Lortie K, Shenassa H, Chen I, Singh SS. Treatment of Asherman's syndrome in an outpatient hysteroscopy setting. J Minim Invasive Gynecol. 2015;22(3):446-450.

58. Broome JD, Vancaillie TG. Fluoroscopically guided hysteroscopic division of adhesions in severe Asherman syndrome. Obstet Gynecol. 1999;93(6):1041-1043.

59. Xu W, Zhang Y, Yang Y, Zhang S, Lin X. Effect of early second-look hysteroscopy on reproductive outcomes after hysteroscopic adhesiolysis in patients with intrauterine adhesion, a retrospective study in China. Int J Surg. 2018;50:49-54.

60. Robinson JK, Colimon LMS, Isaacson KB. Postoperative adhesiolysis therapy for intrauterine adhesions (Asherman's syndrome). Fertil Steril. 2008;90(2):409-414. 
61. Dawood A, Al-Talib A, Tulandi T. Predisposing factors and treatment outcome of different stages of intrauterine adhesions. J Obstet Gynaecol Can. 2010;32(8):767-770.

62. Orhue AAE, Aziken ME, Igbefoh JO. A comparison of two adjunctive treatments for intrauterine adhesions following lysis. Int J Gynaecol Obstet. 2003;82(1):49-56.

63. Zikopoulos KA, Kolibianakis EM, Platteau P, et al. Live delivery rates in subfertile women with Asherman's syndrome after hysteroscopic adhesiolysis using the resectoscope or the Versapoint system. Reprod Biomed Online. 2004;8(6):720-725.

64. Myers EM, Hurst BS. Comprehensive management of severe Asherman syndrome and amenorrhea. Fertil Steril. 2012;97(1):160-164.

65. Salma U, Xue M, Md Sayed AS, Xu D. Efficacy of intrauterine device in the treatment of intrauterine adhesions. Biomed Res Int. 2014; 2014(5):1-15.

66. Malhotra N, Bahadur A, Kalaivani M, Mittal S. Changes in endometrial receptivity in women with Asherman's syndrome undergoing hysteroscopic adhesiolysis. Arch Gynecol Obstet. 2012;286(2):525-530.

67. Johary J, Xue M, Zhu X, Xu D, Velu PP. Efficacy of estrogen therapy in patients with intrauterine adhesions: systematic review. J Minim Invasive Gynecol. 2014;21(1):44-54.

68. Thomson AJM, Abbott JA, Kingston A, Lenart M, Vancaillie TG. Fluoroscopically guided synechiolysis for patients with Asherman's syndrome: menstrual and fertility outcomes. Fertil Steril. 2007;87(2): $405-410$.

69. Liu L, Huang X, Xia E, Zhang X, Li TC, Liu Y. A cohort study comparing $4 \mathrm{mg}$ and $10 \mathrm{mg}$ daily doses of postoperative oestradiol therapy to prevent adhesion reformation after hysteroscopic adhesiolysis. Hum Fertil. 2018;48:1-7.

70. Guo J, Li TC, Liu Y, et al. A prospective, randomized, controlled trial comparing two doses of oestrogen therapy after hysteroscopic adhesiolysis to prevent intrauterine adhesion recurrence. Reprod Biomed Online. 2017;35(5):555-561.

71. Acunzo G, Guida M, Pellicano M, et al. Effectiveness of auto-crosslinked hyaluronic acid gel in the prevention of intrauterine adhesions after hysteroscopic adhesiolysis: a prospective, randomized, controlled study. Hum Reprod. 2003;18(9):1918-1921.

72. Lin XN, Zhou F, Wei ML, et al. Randomized, controlled trial comparing the efficacy of intrauterine balloon and intrauterine contraceptive device in the prevention of adhesion reformation after hysteroscopic adhesiolysis. Fertil Steril. 2015;104(1):235-240.

73. March CM. Management of Asherman's syndrome. Reprod Biomed Online. 2011;23(1):63-76.
74. Kilic S, Yuksel B, Pinarli F, Albayrak A, Boztok B, Delibasi T. Effect of stem cell application on Asherman syndrome, an experimental rat model. J Assist Reprod Genet. 2014;31(8):975-982.

75. Alawadhi F, Du H, Cakmak H, Taylor HS. Bone marrow-derived stem cell (BMDSC) transplantation improves fertility in a murine model of Asherman's syndrome. PLoS One. 2014;9(5):e96662.

76. Wang J, Ju B, Pan C, et al. Application of bone marrow-derived mesenchymal stem cells in the treatment of intrauterine adhesions in rats. Cell Physiol Biochem. 2016;39(4):1553-1560.

77. Gan L, Duan H, Xu Q, et al. Human amniotic mesenchymal stromal cell transplantation improves endometrial regeneration in rodent models of intrauterine adhesions. Cytotherapy. 2017;19(5):603-616.

78. Domnina A, Novikova P, Obidina J, et al. Human mesenchymal stem cells in spheroids improve fertility in model animals with damaged endometrium. Stem Cell Res Ther. 2018;9(1):50.

79. Nagori CB, Panchal SY, Patel H. Endometrial regeneration using autologous adult stem cells followed by conception by in vitro fertilization in a patient of severe Asherman's syndrome. J Human Reprod Sci. 2011;4(1):43-48.

80. Singh N, Mohanty S, Seth T, Shankar M, Bhaskaran S, Dharmendra S. Autologous stem cell transplantation in refractory Asherman's syndrome: a novel cell based therapy. J Hum Reprod Sci. 2014;7(2):93-98.

81. Santamaria X, Cabanillas S, Cervelló I, et al. Autologous cell therapy with CD133+ bone marrow-derived stem cells for refractory Asherman's syndrome and endometrial atrophy: a pilot cohort study. Hum Reprod. 2016;31(5):1087-1096.

82. Tan J, Li P, Wang Q, et al. Autologous menstrual blood-derived stromal cells transplantation for severe Asherman's syndrome. Hum Reprod. 2016;31(12):2723-2729.

83. Baradwan S, Baradwan A, Bashir M, Al-Jaroudi D. The birth weight in pregnant women with Asherman syndrome compared to normal intrauterine cavity: a case-control study. Medicine. 2018;97(32):e11797.

84. Friedman A, Defazio J, Decherney A. Severe obstetric complications after aggressive treatment of Asherman syndrome. Obstet Gynecol. 1986;67(6):864-867.

85. Siegler AM, Valle RF. Therapeutic hysteroscopic procedures. Fertil Steril. 1988;50(5):685-701.

86. Engelbrechtsen L, Langhoff-Roos J, Kjer JJ, Istre O. Placenta accreta: adherent placenta due to Asherman syndrome. Clin Case Rep. 2015; 3(3):175-178.

87. Thinkhamrop J, Laopaiboon M, Lumbiganon P. Prophylactic antibiotics for transcervical procedures. Cochrane Database Syst Rev. 2007;3: CD005637.
International Journal of Women's Health

\section{Publish your work in this journal}

The International Journal of Women's Health is an international, peerreviewed open-access journal publishing original research, reports, editorials, reviews and commentaries on all aspects of women's healthcare including gynecology, obstetrics, and breast cancer. The manuscript management system is completely online and includes
Dovepress

a very quick and fair peer-review system, which is all easy to use. Visit http://www.dovepress.com/testimonials.php to read real quotes from published authors. 